\title{
Alterations in PACAP-38-like immunoreactivity in the plasma during ictal and interictal periods of migraine patients
}

Bernadett Tuka ${ }^{1,3}$, Zsuzsanna Helyes ${ }^{2,4}$, Adrienn Markovics ${ }^{2,4}$, Teréz Bagoly ${ }^{2}$, János Szolcsányi ${ }^{2}$, Nikoletta Szabó ${ }^{1,5}$, Eszter Tóth ${ }^{1}$, Zsigmond Tamás Kincses ${ }^{1,5}$, László Vécsei ${ }^{1,3}$, János Tajti ${ }^{*}$

${ }^{1}$ Department of Neurology, Faculty of Medicine, University of Szeged, H-6725 Szeged, Semmelweis u. 6, Hungary

${ }^{2}$ Department of Pharmacology and Pharmacotherapy, Faculty of Medicine, University of Pécs, H-7624 Pécs, Szigeti u. 12, Hungary

${ }^{3}$ Neuroscience Research Group of the Hungarian Academy of Sciences and University of Szeged, H-6725 Szeged, Semmelweis u. 6, Hungary

${ }^{4}$ János Szentágothai Research Center, University of Pécs, H-7624, Ifjúság útja 20, Hungary ${ }^{5}$ International Clinical Research Center, St. Anne's University Hospital Brno, Brno, Czech Republic

${ }^{*}$ Corresponding author:

János Tajti

H-6725 Szeged, Semmelweis u. 6, Hungary

Tel.: +36 62544576

Fax.: +36 62545597

E-mail address: tajti.janos@med.u-szeged.hu

Keywords: migraine, ictal/interictal periods, plasma PACAP-38-LI

\section{Top five key references:}

1.) Schytz HW, Birk S, Wienecke T, Kruuse C, Olesen J, Ashina M. PACAP38 induces migraine-like attacks in patients with migraine without aura. Brain. 2009; 132:16-25. henrikschytz@hotmail.com

2.) Goadsby PJ. Calcitonin gene-related peptide antagonists as treatments of migraine and other primary headaches. Drugs. 2005; 65:2557-67. peter.goadsby@ucsf.edu 
3.) Gupta S, Bhatt DK, Boni LJ, Olesen J. Improvement of the closed cranial window model in rats by intracarotid infusion of signalling molecules implicated in migraine. Cephalalgia. 2010; 30:27-36.

jes.olesen@regionh.dk

4.) Edvinsson L, Petersen KA. CGRP-receptor antagonism in migraine treatment. CNS Neurol Disord Drug Targets. 2007; 6:240-6.

lars.edvinsson@med.lu.se

5.) Hansen JM, Hauge AW, Olesen J, Ashina M. Calcitonin gene-related peptide triggers migraine-like attacks in patients with migraine with aura. Cephalalgia. 2010; 30:117986.

ashina@dadlnet.dk 


\begin{abstract}
Background: Recent studies on migraineurs and our own animal experiments have revealed that pituitary adenylate cyclase-activating polypeptide-38 (PACAP-38) has an important role in activation of the trigeminovascular system. The aim of this study was to determine the PACAP-38-like immunoreactivity (LI) in the plasma in healthy subjects, and parallel with the calcitonin gene-related peptide (CGRP)-LI in migraine patients in the ictal and interictal periods.
\end{abstract}

Methods: 87 migraineurs and 40 healthy control volunteers were enrolled in the examination. Blood samples were collected from the cubital veins in both periods in 21 patients, and in either the ictal or the interictal period in the remaining 66 patients, and were analyzed by radioimmunoassay.

Results: A significantly lower PACAP-38-LI was measured in the interictal plasma of the migraineurs as compared with the healthy control group $(\mathrm{p}<0.011)$. In contrast, elevated peptide levels was detected in the ictal period relative to the attack-free period in the 21 migraineurs $\left(\mathrm{p}_{\mathrm{PACAP}-38}<0.001 ; \mathrm{p}_{\mathrm{CGRP}}<0.035\right)$ and PACAP-38-LI in the overall population of migraineurs $(\mathrm{p}<0.009)$. A negative correlation was observed between the interictal PACAP38-LI and the disease duration.

Conclusion: This is the first study that has provided evidence of a clear association between migraine phases (ictal and interictal) and plasma PACAP-38-LI alterations. 


\section{Introduction}

It is possible to analyse the mechanisms of pain in animal models, but there are no really clinically relevant systems to appropriately mimic the human specificity of headache diseases. Human investigations are therefore particularly important to identify the key mediators responsible for the development and progression of migraine.

Several hypotheses have been proposed to explain the pathological mechanisms of migraine. One of the most widely accepted theories relates to activation of the trigeminovascular system (TS), which involves vascular and neuronal elements (1). The TS consists of the primary sensory pseudounipolar neurons in the trigeminal ganglion (TRIG), its terminals, and the meningeal vasculature. The peripheral afferents innervate the supratentorial dura mater, the dural vasculature and the large and small pial arteries on the surface of the brain. The central fibres project to the area of the second-order neurons in the brainstem, the caudal trigeminal nucleus (TNC). The third-order neurons are located in the thalamus. The activation mechanism involves the release of neuropeptides from the terminals (e.g. calcitonin gene-related peptide (CGRP), vasoactive intestinal peptide (VIP) and substance P (SP) (2), and functional changes such as neurogenic inflammation (protein extravasation and vasodilatation), mast cell degranulation and sensitization (3).

Among the numerous "migraine-related" processes and substances, the vasoactive pituitary adenylate cyclase-activating polypeptide (PACAP) has been potentially implicated in the pathophysiology of migraine $(4,5)$. PACAP belongs to the VIP/secretin/glucagon neuropeptide superfamily, and is considered to be a "brain-gut peptide", by virtue of its widespread expression and functions in the human body. PACAP exists in two forms: PACAP-27 and PACAP-38; the latter is expressed predominantly in mammals. PACAP acts at one specific $\left(\mathrm{PAC}_{1}\right)$ and two non-specific receptors, which are shared between PACAP and VIP (VPAC 1 and $\mathrm{VPAC}_{2}$ ). This can be explained by the $68 \%$ structural homology between PACAP and VIP (6-8).

This implies that PACAP-38 also has a vasodilatating effect (9), and a broad range of data suggest that it is an integrator of nociceptive and sensitization processes, besides being involved in neurogenic inflammation (10-13).

PACAP is presented in the primary sensory neurons of the TRIG (14), the parasympathetic otic and the sphenopalatine ganglia $(15,16)$. Moreover, PACAP-38 is found in the cell bodies and nerve fibres of the human TNC and the upper regions of the cervical spinal cord, which suggests that PACAP may be closely related to the TS $(2,17)$. We earlier furnished evidence for this hypothesis with animal experimental results. PACAP-deficient mice displayed 
reduced light-aversive behaviour (photophobia), while decreased meningeal blood flow and c-fos expression in the TRIG and TNC were detected relative to wild-type mice after nitroglycerol (NTG)-induced TS activation (18). Further, elevated levels of PACAP-27 and PACAP-38 were measured in the plasma and the TNC 90 and $180 \mathrm{~min}$ after the respective stimulation in two animal models of TS activation (19). These results suggest that PACAP may be an important mediator, and therefore a diagnostic marker of TS activation.

The available human data point to the involvement of PACAP in the mechanisms of migraine. Schytz et al. demonstrated that the intravenous administration of PACAP-38 causes headache in healthy subjects, and migraine-like attacks in migraine patients without aura, $6 \mathrm{~h}$ in average after starting the infusion (4). However, no clinical data are available on endogenous alterations in PACAP levels in relation to migraine.

Based on the literature, we have hypothesized that the plasma concentration of PACAP-38 increases during migraine attacks. Our aims were therefore to reveal the potential relationships between the PACAP-38 levels of the human plasma and the presence of migraine headache. Radioimmunoassay (RIA) measurements were carried out in peripheral blood plasma samples in order to show alterations of PACAP-38-like immunoreactivity (PACAP-38-LI) in migraine patients during the ictal and interictal periods in comparison with healthy control subjects. In addition, the clinical features of the disease, as well as plasma CGRP-like immunoreactivity (CGRP-LI) were also compared to the PACAP-38-LI to explore possible correlations.

\section{Materials and methods}

\section{Participants}

87 migraine patients with or without aura and 40 healthy control subjects were enrolled in this study. The migraineurs were selected in accordance with the criteria of the Headache Classification Committee of the International Headache Society 2004 (20). The study groups were age-matched. The demographic and clinical characteristics of the patient and control populations are summarized in Table 1.

A detailed questionnaire was used to compile a homogeneous group of migraineurs as concerns the features of their migraine disease: the duration of the migraine, the attack frequency, allodynia (21), the severity of pain during attacks as measured on a visualanalogue scale (VAS). The relation of the migraine attacks to the menstrual cycle (22) and to the presence of other non-migraine, chronic pain disorder (lumbago, low-back pain, knee- 
and hip-joint arthrosis) was also assessed. Depression was not clinically diagnosed in any of the cases. Healthy volunteers serving as controls were screened for non-reported/non-treated headaches. Subjects (both patients and controls) who displayed any significant and serious non-migraine chronic disorders were excluded from the study.

\section{Study design and procedures}

The study was approved by the Ethics Committee of the Faculty of Medicine, University of Szeged (87/2009). All study participants gave their written informed consent, in accordance with the Declaration of Helsinki. There were no restrictions as regards food and drink intake. Blood samples were drawn from migraineurs during an attack and/or in an attack-free period. Affected patients were asked not to start their usual attack treatment until blood samples had been taken. Accordingly, 80 interictal and 28 ictal samples were collected. From among the 87 patients, blood samples could be collected in both periods from 21 migraineurs. Data of the population of 21 migraineurs are shown in Table 2. A single blood sample was taken from each control. Blood samples $(6 \mathrm{ml}$ per subject) were taken in a sitting position during rest from the cubital vein and collected in ice-cold glass tubes containing the anticoagulant (ethylenediaminetetraacetic acid (EDTA, $12 \mathrm{mg}$ ) and the protease inhibitor aprotinin (Trasylol, $1200 \mathrm{IU}$ ), and kept at $4{ }^{\circ} \mathrm{C}$ until centrifugation $\left(2000 \mathrm{rpm}\right.$ for $10 \mathrm{~min}$ at $4{ }^{\circ} \mathrm{C}$ ). Plasma samples were stored at $-80{ }^{\circ} \mathrm{C}$ until the PACAP-38-LI- and CGRP-LI were measured by RIA.

\section{RIA measurements and data acquisition}

Plasma concentrations of PACAP-38 were determined with specific and sensitive RIA techniques developed earlier in our laboratory (23). The PACAP-38 antiserum 88111-3 was raised in rabbits with synthetic peptides conjugated to bovine serum albumin (BSA) or thyroglobulin with glutaraldehyde or carbodiimide. The high specificity and C-terminal sensitivity of this antibody were confirmed by cross-reactivity studies, and no cross-reactivity was found with PACAP-27 or with other related neuropeptides in either case. Following centrifugation of the plasma samples $\left(2000 \mathrm{rpm}\right.$ at $4{ }^{\circ} \mathrm{C}$ for $\left.10 \mathrm{~min}\right)$, the peptide was extracted from the plasma into 3 volumes of absolute alcohol.

After precipitation and a second centrifugation $\left(2000 \mathrm{rpm}\right.$ at $4{ }^{\circ} \mathrm{C}$ for $\left.10 \mathrm{~min}\right)$, the samples were dried under a nitrogen flow and resuspended in $300 \mu \mathrm{l}$ of assay buffer before RIA determination in order to achieve a 10-times higher concentration for the RIA procedure (10, 23). The tracers were mono- ${ }^{125}$ I-labelled peptides prepared in our laboratory. Synthetic 
peptides were used as RIA standards in concentrations ranging from 0 to $1000 \mathrm{fmol} / \mathrm{ml}$. The assay was prepared in $1 \mathrm{ml} 0.05 \mathrm{M}(\mathrm{pH}$ 7.4) phosphate buffer containing $0.1 \mathrm{M}$ sodium chloride, $0.25 \%(\mathrm{w} / \mathrm{v}) \mathrm{BSA}$ and $0.05 \%(\mathrm{w} / \mathrm{v})$ sodium azide. The antiserum $(100 \mu 1,1: 10,000$ dilution), the RIA tracer $(100 \mu 1,5000 \mathrm{cpm} /$ tube $)$ and the standard or unknown samples (100 $\mu 1)$ were measured into polypropylene tubes with the assay buffer. After incubation for 48-72 $\mathrm{h}$ at $4{ }^{\circ} \mathrm{C}$, the antibody-bound peptide was separated from the free peptide by the addition of $100 \mu \mathrm{l}$ of separating solution (10 g charcoal, $1 \mathrm{~g}$ dextran and $0.5 \mathrm{~g}$ commercial fat-free milk powder in $100 \mathrm{ml}$ of distilled water). Following centrifugation ( $3000 \mathrm{rpm}$ at $4{ }^{\circ} \mathrm{C}$ for $15 \mathrm{~min}$ ), the contents of the tubes were gently decanted and the radioactivity of the precipitates was measured in a gamma counter (Gamma, type NZ310). The PACAP-38 concentrations of the unknown samples were read from calibration curves.

\section{Statistical analysis}

Data expressed as means \pm SD if not stated otherwise. The normality of the data was tested with the Shapiro-Wilk test. Group comparisons were carried out with the Student's unpaired, paired t-tests and the Wilcoxon-test with SPSS 17.0. Data were analysed with multivariate test (repeated measure ANOVA) in the case of menstruation cycle and chronic pain condition related to PACAP-38 level. Statistical significance was accepted at $\mathrm{p}<0.05$.

\section{Results}

Differences in plasma PACAP-38-LI between migraineurs and healthy controls As concerns the total of 87 migraine patients $(n=87)$, a significantly lower PACAP-38-LI was determined in the interictal plasma of the migraineurs $(n=80 ; 24.60 \pm 3.59 \mathrm{fmol} / \mathrm{ml})$ than in that of the healthy volunteers $(n=40 ; 26.54 \pm 4.43 \mathrm{fmol} / \mathrm{ml}$; Student's unpaired t-test, $\mathrm{p}<0.011$, $\mathrm{t}=2.578$ ) (Fig. 1/A). However, the plasma samples from the patients during their migraine attacks $(n=28)$ exhibited a significantly higher PACAP-38 concentration $(27.39 \pm 4.67$ $\mathrm{fmol} / \mathrm{ml})$ as compared with the interictal samples $(\mathrm{n}=59 ; 24.91 \pm 3.73 \mathrm{fmol} / \mathrm{ml}$; Student's unpaired t-test, $\mathrm{p}<0.009, \mathrm{t}=-2.676$ ) (the interictal data of those 21 migraineurs whose plasma samples were collected from both periods were excluded from this analysis to avoid the statistical problems caused by the paired samples) (Fig. 1/B). No difference was found when the ictal samples were compared with those of the controls (Student's t-test for unpaired comparisons, $\mathrm{p}<0.447, \mathrm{t}=-0.765$ ) (Fig. $1 / \mathrm{C}$ ). 
A negative correlation was found between the duration of the migraine and the interictal PACAP-38-LI ( $\mathrm{n}=87$; linear regression, $\mathrm{p}<0.044$, $\mathrm{R}=0.231$ ) (Fig. 2). Plasma PACAP-38-LI did not correlate with the age, attack frequency, allodynia, and the VAS-score (ANOVA, linear regression, $\mathrm{p}>0.05$ ) or differences were not found regarding the gender, hormonal changes and pain (Student's unpaired t-test, $\mathrm{p}>0.05$ ).

\section{Changes in plasma PACAP-38-LI and CGRP-LI in 21 migraineurs}

To gain insight into the changes of neuropeptide levels, we measured the plasma concentrations of PACAP-38 and CGRP plasma concentration in the same subject during a headache attack and interictally. The plasma PACAP-38-LI was significantly higher in the ictal period $(28.04 \pm 5.00 \mathrm{fmol} / \mathrm{ml})$ than in the interictal period $(23.74 \pm 3.09 \mathrm{fmol} / \mathrm{ml})(\mathrm{n}=21$; Student's paired t-test, $\mathrm{p}<0.001, \mathrm{t}=-4.134$ ) (Fig. 3/A).

The CGRP-LI was determined simultaneously with the PACAP-38-LI in both phases in 18 migraineurs. Significantly higher CGRP levels were observed in the plasma samples during the ictal period $(53.74 \pm 31.52 \mathrm{fmol} / \mathrm{ml})$ as compared with the interictal period $(39.74 \pm 27.49$ fmol/ml) (n=18; Wilcoxon-test, p<0.035) (Fig. 3/B).

Associations of changes in plasma PACAP-38-LI with the menstruation cycle sensitivity and chronic pain conditions in 21 migraineurs

Changes in the plasma PACAP-38-LI proved to be influenced by 2 parameters: There was a significant PACAP-38-LI elevation in the ictal phase $(31.01 \pm 3.32)$ compared to the interictal phase $(24.18 \pm 2.52)$ in patients whose migraine headache was not sensitive to the menstruation cycle (Group 1: $\mathrm{n}=11$; Student's paired t-test, $\mathrm{p}<0.00002, \mathrm{t}=-7.250$ ). Meanwhile, there was no such significant increase during the ictal phase $(24.78 \pm 4.56)$ compared to the interictal phase $(23.26 \pm 3.70)$ in patients whose migraine headache was sensitive to the menstruation cycle (Group 2: $\mathrm{n}=10$; Student's paired t-test, $\mathrm{p}<0.344$, $\mathrm{t}=-0.998$ ) (Fig. 4). Similar PACAP-38-LI increase was detected in the ictal phase $(30.01 \pm 3.69)$ vs. the interictal phase $(24.15 \pm 2.47)$ of patients, who did not have chronic pain-related conditions (Group 1: $\mathrm{n}=15$; Student's paired t-test, $\mathrm{p}<0.00005, \mathrm{t}=-5.716$ ). However, there was no difference in the ictal phase $(23.13 \pm 4.64)$ compared to the interictal phase $(22.71 \pm 4.40)$ in patients, who had other non-migraine, chronic pain disorders (Group 2: $\mathrm{n}=6$; Student's paired t-test, $\mathrm{p}<0.833$, $\mathrm{t}=-0.222$ ) (Fig. 5).

To reveal the relationship between ictal-interictal PACAP-38 levels and mentruation and chronic pain, repeated measure ANOVA was used. Multivariate test showed significant main effect of PACAP-38 measurements in different phases of the disease $(F(1,19)=22.579$, 
$\mathrm{p}<0.0001)$ and main effect of headache related to the menstruation cycle $(\mathrm{F}(1,19)=22.257$, $\mathrm{p}<0.0001)$. The interaction of the two factors was also significant $(F(1,19)=9.096, p<0.007)$. Similar ANOVA was carried out for identifying if ictal/interictal PACAP-38 level changes are influenced by concomitant chronic pain conditions. While significant main effects were identified by analysis (ictal/interictal: $F(1,19)=11.392, p<0.003$, chronic pain condition: $F(1,19)=0.553, p<0.446)$ the interaction was not significant in this case $(p>0.05)$.

No correlations were found between the level of peptides and age, gender, the attack frequency, allodynia or the VAS-score.

\section{Discussion}

This study provided the first evidence that the PACAP-38 concentration in the plasma of migraineurs is significantly lower in the interictal period as compared with that in healthy volunteers, but increases during migraine attacks relative to the attack-free period. These results suggest that PACAP-38 might be an important mediator of the pathophysiology of migraine. The difference in the plasma levels of PACAP-38 in migraineurs in the two periods indicate that this peptide is involved in the development of the attacks.

Effects of PACAP-38 related to migraine

PACAP-38 can be released from both the central and the peripheral terminals of the pseudounipolar neurons of the TRIG (24) in response to specific triggers. It enters the systemic circulation, and binds to its receptors $\left(\mathrm{PAC}_{1}, \mathrm{VPAC}_{1}\right.$ and $\left.\mathrm{VPAC}_{2}\right)$ on the meningeal vessels and second-order sensory neurons. Zagami and co-workers published (25) that the stimulation of the superior sagittal sinus causes extracranial release of PACAP. PACAP is known to induce neurogenic inflammation, mast cell degranulation, neuronal activation and sensitization $(4,26)$. These effects can contribute to the development of severe headache and possibly to aggravation of the attacks.

An MRI angiographic study revealed that PACAP-38 infusion-induced headache is related to significant dilatation of the middle meningeal arteries (MMAs), in contrast with the middle cerebral arteries (27). The intracarotid infusion of PACAP-38 produces significant dilatation of the dural artery in the rat, and this administration route has proved to be more effective than the intravenous mode (28). PACAP-38 also exerts potent vasodilating action on pressurized MMAs, which can be influenced by a $\mathrm{PAC}_{1}$ receptor antagonist. Multiple variants of the $\mathrm{PAC}_{1}$ receptor have been found besides the $\mathrm{VPAC}_{2}$ receptors in the rat MMAs (29). 
PACAP and VIP receptors in the human meningeal and coronary arteries were recently characterized with pharmacological modulators, and these peptides were found to have lower potency and efficacy in meningeal vasculature than in coronary arteries. This study concluded that processes of PACAP-38-induced migraine-like headache may not involve meningeal vasodilatation rather than sensitization of peripheral and central sensory trigeminal fibres (9). The reported effects of a PACAP infusion regarding neurogenic inflammation and mast cell degranulation in relation to migraine are controversial (26). It was concluded from a study of the mast cell degranulating effects of different truncated PACAP and VIP fragments on rat peritoneal and dural mast cells that phospholipase C-mediated mast cell degranulation is implicated in PACAP-induced migraine (30).

\section{Possible mechanisms related to the elevated PACAP-38-LI during migraine attacks}

There are some anatomical and physiological factors, which might be involved in the migraine-like headache inducing effect of PACAP-38.

A.) PACAP-38 is a sensory (14), sympathetic (15) and parasympathetic (16) neuropeptide (31), which is released from the nerve endings $(2,14,17,32)$ at the dural or other cranial compartments. It can modulate both vessels and nerve fibres through its receptors leading to elevated intracellular cyclic adenosine monophosphate (cAMP) levels (33). There are several lines of evidence that the increased cAMP cause sensitization and activation of the trigeminal neurons (34) and meningeal nociceptors $(35,36)$, therefore induce delayed headache (37).

The headache-inducing action of PACAP-38 was first described in 2009 by Schytz and coworkers, who demonstrated that PACAP-38 has a simple headache-evoking effect in healthy volunteers, but provokes severe migraine-like attacks in susceptible subjects. A decreased mean blood flow velocity in the middle cerebral artery and an increase in diameter of the superficial temporal artery were observed 20 min following the infusion (4). It is possible that that PACAP-38 has a positive feedback, self-amplifying effect, which can contribute to the maintenance and aggravation of the headache.

Based on similar features and receptors of PACAP and VIP, as well as the supposed complex mechanism of migraine, it is likely that migraine cannot be related only to PACAP-38. Its causative role is equivocal, but its involvement is unquestioned.

This peptide can contribute to the evolution of migraine attacks in co-operation with other regulatory neuropeptides, molecules and enzymes, like VIP, CGRP, 5-HT, SP and NO. When the headache starts in response to specific triggers (vasodilatation - plasma protein extravasation - mast cell degranulation - neuropeptide release - neurogenic inflammation) the 
presence and aggravation of pain may lead to the release of PACAP-38 from the nerve terminals, as a self-triggering process. This can be an explanation for the finding that the increase of plasma PACAP-38-LI in the ictal phases of migraineurs compared to the interictal one is moderate, but significant.

B.) Numerous studies have approached the effects of PACAP-38 involved in headache from vasodilating aspects. There are controversial result regarding the relaxing actions of PACAP-38 on meningeal or cerebral, arteries $(9,29,38,39)$. The vasodilating properties in a small extent or indirectly is likely to contribute to the development of the headache, e. g. PACAP induces vascular effects mediated via activation of perivascular nerves (40). The vascular effects cannot be excluded, but based on the literature it seems that these may be less relevant in migraine (9). PACAP-38 is more potent to sensitize trigeminal peripheral sensory fibres directly and also through mast cell degranulation $(4,26,30)$. These mechanisms can be related to the phenomenon of throbbing headache, which can correlate with the increased PACAP-38-LI during the ictal phase of migraineurs found in our study. Subsequently, it would be plausible that the activation of the second order trigeminal neurons by PACAP-38 can result in a direct central sensitization (4).

Complementary mechanisms behind reduced PACAP-38-LI during interictal phase of migraine patients

The lower concentration of PACAP-38 observed in the interictal period, and especially the correlation of the interictal plasma PACAP-38-LI with the disease duration, might be explained indirectly in terms of brain energy deficit (an impairment of the cerebral and striated muscle energy metabolism (41, 42), elevated lactate levels (43, 44), abnormalities of mitochondrial compartments (45) and imbalanced $\mathrm{Mg}^{2+}$ concentration in the neurons $(46,47))$.

It may additionally be hypothesized that the low interictal peptide concentration might be associated with degenerative changes affecting the PACAP-releasing circuitries (cortical atrophy (48), iron deposition in the periaqueductal grey matter (49), and increased levels of markers indicative of neuronal and glial damage (50)).

\section{The possible role of the blood-brain barrier $(B B B)$}

The ability of PACAP to pass through the intact BBB is limited; it needs specific transporters in specific brain areas $(51,52)$. However, the enhanced BBB permeability in migraine may allow PACAP to penetrate into the cerebrospinal fluid and exert its central effects. From the 
opposite aspect, the PACAP released in the brain (6) can also penetrate through the BBB, and hence may be detected in the plasma. There are assumptions that the integrity of the BBB is disrupted in migraineurs $(53,54)$. A transient brain dysfunction, vasogenic cerebral oedema and a damaged BBB can develop in lipopolysaccharide-induced brain injury in rats in response to the over-expression of matrix metalloproteinase 9 (55). This enzyme can degrade the basal membrane, resulting in structural impairment of the BBB, and altered plasma levels of which have been observed in patients with migraine (56-59).

Correlation of PACAP-38-LI with the menstruation cycle and other chronic pain conditions in migraineurs

Migraine attacks are often closely related to female hormonal changes (22). Hence, it is interesting that PACAP-38-LI increases significantly during the ictal period only in those women whose headache is not related to the menstrual cycle. Although, the influence of the menstruation cycle in the PACAP-38-LI changes cannot be excluded, but there is evidence that the plasma concentration of PACAP-38 is relatively stable and independent of the gender, age, food intake or female hormonal cycles in healthy subjects (60).

It is well established that PACAP-38 plays an important role in a variety of other pain conditions (61-63). In opposition there was no increased PACAP-38 LI in the ictal phase in patients with other chronic pain conditions. Moreover, we did not find any statistical proof of the influence of the chronic pain and the alterations of the PACAP-38 level.

\section{Possible relations between the PACAP-38 and CGRP in migraineurs}

More than 20 years ago, the release of CGRP was demonstrated in the extracerebral circulation of humans and cats in response to TS activation $(64,65)$. CGRP-containing neurons have been detected in the human TRIG $(14,66)$ and elevated plasma CGRP levels have been described in migraine $(67,68)$ and other types of primary headache $(69)$. Moreover, an intravenous infusion of human alpha-CGRP causes migraine headache $(37,70)$ and there is a significant positive correlation between plasma levels of CGRP and headache severity scores in NTG-induced migraine attacks (71). However, one controversial study questions the importance of CGRP in migraine (72). In fact, CGRP-receptor antagonists are effective in the treatment of migraine disorder (73), but their side-effect profile, with special emphasis on hepatotoxicity, currently makes this drug development direction problematic (74-76). Our results draw attention to a possible influence between the PACAP and CGRP systems in migraine pathogenesis. 


\section{Conclusions}

It is concluded that PACAP-38 might be implicated in the development of migraine headache. There is association between migraine periods (ictal and interictal) and alterations in PACAP-38 levels in the plasma. The quantitative changes in this peptide in the plasma are related to the disease duration, the menstruation cycle and the presence of other pain-related disorders. The causative role of PACAP-38 in migraine headache demands further studies. Our results indicate the need for investigations of the role of plasma PACAP-38 as a putative biomarker of migraine, which might provide new perspectives as concerns the identification of a new target in the therapy of migraine.

\section{Acknowledgements}

This work was supported by Hungarian grants: Developing Competitiveness of Universities in the South Transdanubian Region (SROP-4.2.1.B-10/2/KONV-2010-0002, SROP-4.2.2.A-11/1/KONV-2012-0024 and SROP-4.2.2/B-10/1-2010-0029), the Neuroscience Research Group of the Hungarian Academy of Sciences and the University of Szeged, SROP-4.2.1.B-09/1/KONV-2010-0005, K-2012-TÁMOP-4.2.2.A-11/1/KONV.0443534/130, OTKA [PD 104715] and FNUSA-ICRC [CZ.1.05/1.1.00/02.0123]. B. Tuka is a Gedeon Richter Plc.-sponsored PhD candidate. Dr. Kincses was supported by the Bolyai Scholarship Programme of the Hungarian Academy of Sciences. 


\section{References}

1. Tajti J, Pardutz A, Vamos E, Tuka B, Kuris A, Bohar Z, et al. Migraine is a neuronal disease. J Neural Transm. 2011 Apr;118(4):511-24.

2. Tajti J, Uddman R, Edvinsson L. Neuropeptide localization in the "migraine generator" region of the human brainstem. Cephalalgia. 2001 Mar;21(2):96-101.

3. Edvinsson L, Uddman R. Neurobiology in primary headaches. Brain Res Brain Res Rev. 2005 Jun;48(3):438-56.

4. Schytz HW, Birk S, Wienecke T, Kruuse C, Olesen J, Ashina M. PACAP38 induces migraine-like attacks in patients with migraine without aura. Brain. 2009 Jan;132(Pt 1):16-25.

5. Schytz HW, Olesen J, Ashina M. The PACAP receptor: a novel target for migraine treatment. Neurotherapeutics. 2010 Apr;7(2):191-6.

6. Vaudry D, Falluel-Morel A, Bourgault S, Basille M, Burel D, Wurtz O, et al. Pituitary adenylate cyclase-activating polypeptide and its receptors: 20 years after the discovery. Pharmacol Rev. 2009 Sep;61(3):283-357.

7. Arimura A. PACAP: the road to discovery. Peptides. 2007 Sep;28(9):1617-9.

8. Laburthe M, Couvineau A. Molecular pharmacology and structure of VPAC Receptors for VIP and PACAP. Regul Pept. 2002 Oct 15;108(2-3):165-73.

9. Chan KY, Baun M, de Vries R, van den Bogaerdt AJ, Dirven CM, Danser AH, et al. Pharmacological characterization of VIP and PACAP receptors in the human meningeal and coronary artery. Cephalalgia. 2011 Jan;31(2):181-9.

10. Nemeth J, Reglodi D, Pozsgai G, Szabo A, Elekes K, Pinter E, et al. Effect of pituitary adenylate cyclase activating polypeptide-38 on sensory neuropeptide release and neurogenic inflammation in rats and mice. Neuroscience. 2006 Nov 17;143(1):223-30.

11. Helyes Z, Pozsgai G, Borzsei R, Nemeth J, Bagoly T, Mark L, et al. Inhibitory effect of PACAP-38 on acute neurogenic and non-neurogenic inflammatory processes in the rat. Peptides. 2007 Sep;28(9):1847-55.

12. Mabuchi T, Shintani N, Matsumura S, Okuda-Ashitaka E, Hashimoto H, Muratani T, et al. Pituitary adenylate cyclase-activating polypeptide is required for the development of spinal sensitization and induction of neuropathic pain. J Neurosci. 2004 Aug 18;24(33):728391.

13. Zhang Y, Malmberg AB, Sjolund B, Yaksh TL. The effect of pituitary adenylate cyclase activating peptide (PACAP) on the nociceptive formalin test. Neurosci Lett. 1996 Apr 5;207(3):187-90. 
14. Tajti J, Uddman R, Moller S, Sundler F, Edvinsson L. Messenger molecules and receptor mRNA in the human trigeminal ganglion. J Auton Nerv Syst. 1999 May 28;76(23):176-83.

15. Uddman R, Tajti J, Moller S, Sundler F, Edvinsson L. Neuronal messengers and peptide receptors in the human sphenopalatine and otic ganglia. Brain Res. 1999 May $1 ; 826(2): 193-9$.

16. Csati A, Tajti J, Kuris A, Tuka B, Edvinsson L, Warfvinge K. Distribution of vasoactive intestinal peptide, pituitary adenylate cyclase-activating peptide, nitric oxide synthase, and their receptors in human and rat sphenopalatine ganglion. Neuroscience. 2012 Jan 27;202:158-68.

17. Uddman R, Tajti J, Hou M, Sundler F, Edvinsson L. Neuropeptide expression in the human trigeminal nucleus caudalis and in the cervical spinal cord $\mathrm{C} 1$ and $\mathrm{C} 2$. Cephalalgia. 2002 Mar;22(2):112-6.

18. Markovics A, Kormos V, Gaszner B, Lashgarara A, Szoke E, Sandor K, et al. Pituitary adenylate cyclase-activating polypeptide plays a key role in nitroglycerol-induced trigeminovascular activation in mice. Neurobiol Dis. 2012 Jan;45(1):633-44.

19. Tuka B, Helyes Z, Markovics A, Bagoly T, Nemeth J, Mark L, et al. Peripheral and central alterations of pituitary adenylate cyclase activating polypeptide-like immunoreactivity in the rat in response to activation of the trigeminovascular system. Peptides. 2012 Feb;33(2):307-16.

20. Lipton RB, Bigal ME, Steiner TJ, Silberstein SD, Olesen J. Classification of primary headaches. Neurology. 2004 Aug 10;63(3):427-35.

21. Aguggia M. Allodynia and migraine. Neurol Sci. 2012 May;33 Suppl 1:S9-11.

22. Karli N, Baykan B, Ertas M, Zarifoglu M, Siva A, Saip S, et al. Impact of sex hormonal changes on tension-type headache and migraine: a cross-sectional population-based survey in 2,600 women. J Headache Pain. 2012 Oct;13(7):557-65.

23. Jakab B, Reglodi D, Jozsa R, Hollosy T, Tamas A, Lubics A, et al. Distribution of PACAP-38 in the central nervous system of various species determined by a novel radioimmunoassay. J Biochem Biophys Methods. 2004 Oct 29;61(1-2):189-98.

24. Baeres FM, Moller M. Origin of PACAP-immunoreactive nerve fibers innervating the subarachnoidal blood vessels of the rat brain. J Cereb Blood Flow Metab. 2004 Jun;24(6):628-35.

25. A.S. Zagami E, L, Hoskin KL, Goadsby PJ. Stimulation of the superior sagittal sinus causes extracranial release of PACAP. Cephalalgia. 1995;15:109. 
26. Schytz HW. Investigation of carbachol and PACAP38 in a human model of migraine. Dan Med Bull. 2010 Dec;57(12):B4223.

27. Amin FM, Asghar MS, Guo S, Hougaard A, Hansen AE, Schytz HW, et al. Headache and prolonged dilatation of the middle meningeal artery by PACAP38 in healthy volunteers. Cephalalgia. 2012 Jan;32(2):140-9.

28. Gupta S, Bhatt DK, Boni LJ, Olesen J. Improvement of the closed cranial window model in rats by intracarotid infusion of signalling molecules implicated in migraine. Cephalalgia. 2010 Jan;30(1):27-36.

29. Syed AU, Koide M, Braas KM, May V, Wellman GC. Pituitary Adenylate CyclaseActivating Polypeptide (PACAP) Potently Dilates Middle Meningeal Arteries: Implications for Migraine. J Mol Neurosci. 2012 Jul 6.

30. Baun M, Pedersen MH, Olesen J, Jansen-Olesen I. Dural mast cell degranulation is a putative mechanism for headache induced by PACAP-38. Cephalalgia. 2012 Mar;32(4):33745.

31. Knutsson M, Edvinsson L. Distribution of mRNA for VIP and PACAP receptors in human cerebral arteries and cranial ganglia. Neuroreport. 2002 Mar 25;13(4):507-9.

32. Klimaschewski L, Hauser C, Heym C. PACAP immunoreactivity in the rat superior cervical ganglion in comparison to VIP. Neuroreport. 1996 Nov 4;7(15-17):2797-801.

33. Dickson L, Aramori I, McCulloch J, Sharkey J, Finlayson K. A systematic comparison of intracellular cyclic AMP and calcium signalling highlights complexities in human VPAC/PAC receptor pharmacology. Neuropharmacology. 2006 Nov;51(6):1086-98.

34. Ingram SL, Williams JT. Modulation of the hyperpolarization-activated current (Ih) by cyclic nucleotides in guinea-pig primary afferent neurons. J Physiol. 1996 Apr 1;492 ( Pt 1):97-106.

35. Burstein R, Yamamura H, Malick A, Strassman AM. Chemical stimulation of the intracranial dura induces enhanced responses to facial stimulation in brain stem trigeminal neurons. J Neurophysiol. 1998 Feb;79(2):964-82.

36. Strassman AM, Raymond SA, Burstein R. Sensitization of meningeal sensory neurons and the origin of headaches. Nature. 1996 Dec 12;384(6609):560-4.

37. Lassen LH, Haderslev PA, Jacobsen VB, Iversen HK, Sperling B, Olesen J. CGRP may play a causative role in migraine. Cephalalgia. 2002 Feb;22(1):54-61.

38. Jansen-Olesen I, Gulbenkian S, Engel U, Cunha e Sa M, Edvinsson L. Peptidergic and non-peptidergic innervation and vasomotor responses of human lenticulostriate and posterior cerebral arteries. Peptides. 2004 Dec;25(12):2105-14. 
39. Goadsby PJ. The vascular theory of migraine--a great story wrecked by the facts. Brain. 2009 Jan;132(Pt 1):6-7.

40. Uddman R, Goadsby PJ, Jansen I, Edvinsson L. PACAP, a VIP-like peptide: immunohistochemical localization and effect upon cat pial arteries and cerebral blood flow. J Cereb Blood Flow Metab. 1993 Mar;13(2):291-7.

41. Barbiroli B, Montagna P, Cortelli P, Funicello R, Iotti S, Monari L, et al. Abnormal brain and muscle energy metabolism shown by 31P magnetic resonance spectroscopy in patients affected by migraine with aura. Neurology. 1992 Jun;42(6):1209-14.

42. Montagna P, Cortelli P, Barbiroli B. Magnetic resonance spectroscopy studies in migraine. Cephalalgia. 1994 Jun;14(3):184-93.

43. Watanabe H, Kuwabara T, Ohkubo M, Tsuji S, Yuasa T. Elevation of cerebral lactate detected by localized $1 \mathrm{H}$-magnetic resonance spectroscopy in migraine during the interictal period. Neurology. 1996 Oct;47(4):1093-5.

44. Kaufmann P, Shungu DC, Sano MC, Jhung S, Engelstad K, Mitsis E, et al. Cerebral lactic acidosis correlates with neurological impairment in MELAS. Neurology. 2004 Apr 27;62(8):1297-302.

45. Sangiorgi S, Mochi M, Riva R, Cortelli P, Monari L, Pierangeli G, et al. Abnormal platelet mitochondrial function in patients affected by migraine with and without aura. Cephalalgia. 1994 Feb;14(1):21-3.

46. Welch KM, Ramadan NM. Mitochondria, magnesium and migraine. J Neurol Sci. 1995 Dec;134(1-2):9-14.

47. Peikert A, Wilimzig C, Kohne-Volland R. Prophylaxis of migraine with oral magnesium: results from a prospective, multi-center, placebo-controlled and double-blind randomized study. Cephalalgia. 1996 Jun;16(4):257-63.

48. May A. New insights into headache: an update on functional and structural imaging findings. Nat Rev Neurol. 2009 Apr;5(4):199-209.

49. Welch KM, Nagesh V, Aurora SK, Gelman N. Periaqueductal gray matter dysfunction in migraine: cause or the burden of illness? Headache. 2001 Jul-Aug;41(7):62937.

50. Yilmaz N, Karaali K, Ozdem S, Turkay M, Unal A, Dora B. Elevated S100B and neuron specific enolase levels in patients with migraine-without aura: evidence for neurodegeneration? Cell Mol Neurobiol. 2011 May;31(4):579-85. 
51. Nonaka N, Banks WA, Mizushima H, Shioda S, Morley JE. Regional differences in PACAP transport across the blood-brain barrier in mice: a possible influence of strain, amyloid beta protein, and age. Peptides. 2002 Dec;23(12):2197-202.

52. Nonaka N, Farr SA, Nakamachi T, Morley JE, Nakamura M, Shioda S, et al. Intranasal administration of PACAP: Uptake by brain and regional brain targeting with cyclodextrins. Peptides. 2012 Aug;36(2):168-75.

53. Gao HM, Li L, Zhang KL, Chen XH, Tian SQ, Zhang ZL. Impact of migraine attacks on the blood-brain barrier. Chin Med J (Engl). 2010 Sep;123(18):2559-61.

54. Dreier JP, Jurkat-Rott K, Petzold GC, Tomkins O, Klingebiel R, Kopp UA, et al. Opening of the blood-brain barrier preceding cortical edema in a severe attack of FHM type II. Neurology. 2005 Jun 28;64(12):2145-7.

55. Mun-Bryce S, Rosenberg GA. Gelatinase B modulates selective opening of the bloodbrain barrier during inflammation. Am J Physiol. 1998 May;274(5 Pt 2):R1203-11.

56. Ashina M, Tvedskov JF, Lipka K, Bilello J, Penkowa M, Olesen J. Matrix metalloproteinases during and outside of migraine attacks without aura. Cephalalgia. 2010 Mar;30(3):303-10.

57. Leira R, Sobrino T, Rodriguez-Yanez M, Blanco M, Arias S, Castillo J. Mmp-9 immunoreactivity in acute migraine. Headache. 2007 May;47(5):698-702.

58. Gursoy-Ozdemir Y, Qiu J, Matsuoka N, Bolay H, Bermpohl D, Jin H, et al. Cortical spreading depression activates and upregulates MMP-9. J Clin Invest. 2004 May;113(10):1447-55.

59. Martins-Oliveira A, Goncalves FM, Speciali JG, Fontana V, Izidoro-Toledo TC, Belo VA, et al. Specific matrix metalloproteinase 9 (MMP-9) haplotype affect the circulating MMP-9 levels in women with migraine. J Neuroimmunol. 2012 Aug 17.

60. Borzsei R, Mark L, Tamas A, Bagoly T, Bay C, Csanaky K, et al. Presence of pituitary adenylate cyclase activating polypeptide-38 in human plasma and milk. Eur $\mathrm{J}$ Endocrinol. 2009 Apr;160(4):561-5.

61. Sandor K, Bolcskei K, McDougall JJ, Schuelert N, Reglodi D, Elekes K, et al. Divergent peripheral effects of pituitary adenylate cyclase-activating polypeptide-38 on nociception in rats and mice. Pain. 2009 Jan;141(1-2):143-50.

62. Schytz HW, Holst H, Arendt-Nielsen L, Olesen J, Ashina M. Cutaneous nociception and neurogenic inflammation evoked by PACAP38 and VIP. J Headache Pain. 2010 Aug;11(4):309-16. 
63. Dickinson T, Fleetwood-Walker SM. Neuropeptides and nociception: recent advances and therapeutic implications. Trends Pharmacol Sci. 1998 Sep;19(9):346-8.

64. Goadsby PJ, Edvinsson L, Ekman R. Release of vasoactive peptides in the extracerebral circulation of humans and the cat during activation of the trigeminovascular system. Ann Neurol. 1988 Feb;23(2):193-6.

65. Zagami AS, Goadsby PJ, Edvinsson L. Stimulation of the superior sagittal sinus in the cat causes release of vasoactive peptides. Neuropeptides. 1990 Jun;16(2):69-75.

66. Eftekhari S, Salvatore CA, Calamari A, Kane SA, Tajti J, Edvinsson L. Differential distribution of calcitonin gene-related peptide and its receptor components in the human trigeminal ganglion. Neuroscience. 2010 Aug 25;169(2):683-96.

67. Goadsby PJ, Edvinsson L, Ekman R. Vasoactive peptide release in the extracerebral circulation of humans during migraine headache. Ann Neurol. 1990 Aug;28(2):183-7.

68. Ashina M, Bendtsen L, Jensen R, Schifter S, Olesen J. Evidence for increased plasma levels of calcitonin gene-related peptide in migraine outside of attacks. Pain. 2000 May;86(12):133-8.

69. Goadsby PJ. Calcitonin gene-related peptide antagonists as treatments of migraine and other primary headaches. Drugs. 2005;65(18):2557-67.

70. Hansen JM, Hauge AW, Olesen J, Ashina M. Calcitonin gene-related peptide triggers migraine-like attacks in patients with migraine with aura. Cephalalgia. 2010 Oct;30(10):1179-86.

71. Juhasz G, Zsombok T, Modos EA, Olajos S, Jakab B, Nemeth J, et al. NO-induced migraine attack: strong increase in plasma calcitonin gene-related peptide (CGRP) concentration and negative correlation with platelet serotonin release. Pain. 2003 Dec;106(3):461-70.

72. Hansen JM, Thomsen LL, Olesen J, Ashina M. Calcitonin gene-related peptide does not cause migraine attacks in patients with familial hemiplegic migraine. Headache. 2011 Apr;51(4):544-53.

73. Edvinsson L, Linde M. New drugs in migraine treatment and prophylaxis: telcagepant and topiramate. Lancet. 2010 Aug 21;376(9741):645-55.

74. Ho TW, Edvinsson L, Goadsby PJ. CGRP and its receptors provide new insights into migraine pathophysiology. Nat Rev Neurol. 2010 Oct;6(10):573-82.

75. Edvinsson L, Petersen KA. CGRP-receptor antagonism in migraine treatment. CNS Neurol Disord Drug Targets. 2007 Aug;6(4):240-6. 
76. Tfelt-Hansen P, Olesen J. Possible site of action of CGRP antagonists in migraine. Cephalalgia. 2011 Apr;31(6):748-50.

\section{Table and Figure legends}

Tablel

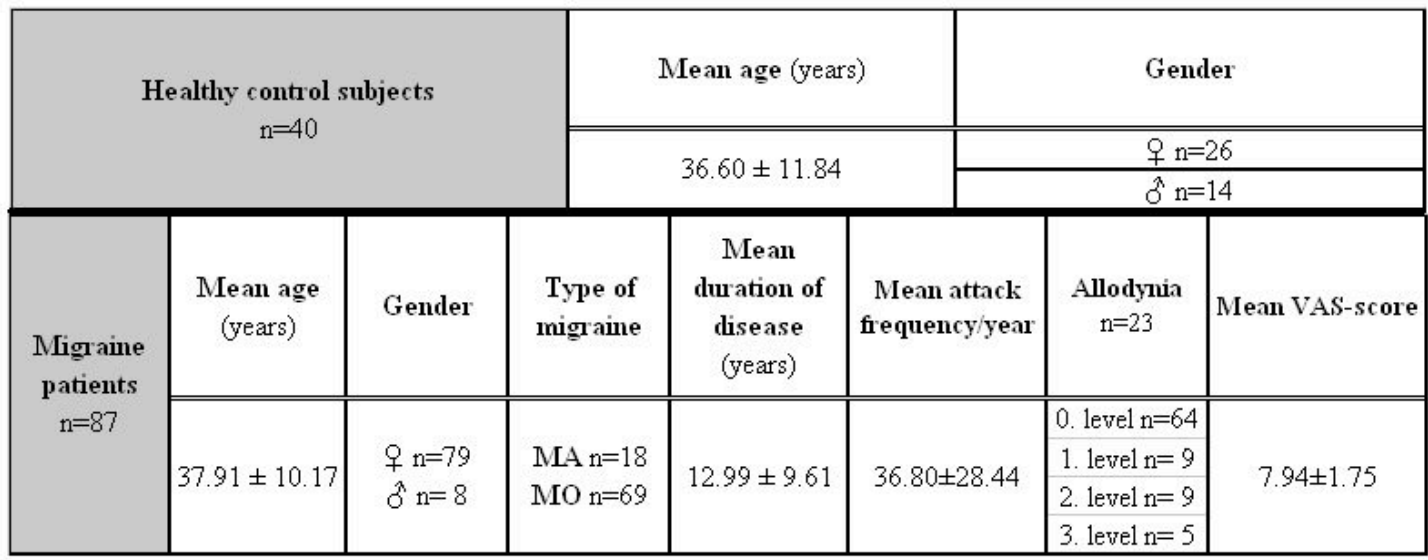

Table 1: Mean data on healthy control volunteers and 87 migraineurs (age, gender, type of migraine (with or without aura), disease duration (years), attack frequency, allodynia, and VAS-score are shown. MA: migraine with aura; MO: migraine without aura. Allodynia: 0: absence of allodynia; 1: mild allodynia; 2: moderate allodynia; 3: serious allodynia.

\begin{tabular}{|c|c|c|c|c|c|c|c|c|c|c|c|}
\hline Patient & Age & Gender & $\begin{array}{c}\text { Type of } \\
\text { migraine }\end{array}$ & $\begin{array}{c}\text { Duration } \\
\text { of disease } \\
\text { (years) }\end{array}$ & $\begin{array}{c}\text { Attack } \\
\text { frequency/ } \\
\text { year }\end{array}$ & Allodynia & $\begin{array}{l}\text { VAS- } \\
\text { score }\end{array}$ & $\begin{array}{c}\text { Interictal } \\
\text { sample } \\
\text { PACAP-38 } \\
(\text { fmol } / \mathrm{ml})\end{array}$ & $\begin{array}{c}\text { Previous } \\
\text { attack } \\
\text { (days ago) }\end{array}$ & $\begin{array}{l}\text { Ictal sample } \\
\text { PACAP-38 } \\
\text { (fmol/ml) }\end{array}$ & $\begin{array}{c}\text { Duration of } \\
\text { headache befor e } \\
\text { sampling } \\
\text { (hours) }\end{array}$ \\
\hline 1 & 24 & q & MO & 3 & 17 & 0 & 10 & 24.30 & 9 & 26.50 & 4 \\
\hline 2 & 39 & $q$ & MO & 26 & 30 & 0 & 9 & 20.00 & 2 & 29.16 & 96 \\
\hline 3 & 46 & $q$ & MO & 18 & 24 & 0 & 9 & 19.50 & 7 & 23.90 & 4 \\
\hline 4 & 44 & $q$ & MO & 30 & 47 & 3 & 7 & 18.40 & 9 & 20.90 & 12 \\
\hline 5 & 45 & $q$ & MO & 2 & 12 & 0 & 9 & 26.94 & 6 & 20.40 & 5 \\
\hline 6 & 27 & $q$ & MO & 14 & 30 & 2 & 8 & 20.50 & 6 & 17.00 & 24 \\
\hline 7 & 35 & $q$ & MO & 20 & 12 & 0 & 8 & 27.00 & 6 & 31.20 & 7 \\
\hline 8 & 39 & $q$ & MO & 30 & 109 & 2 & 9 & 21.20 & 10 & 25.90 & 7 \\
\hline 9 & 31 & 8 & MA & 10 & 52 & 0 & 7 & 24.11 & 7 & 33.21 & 8 \\
\hline 10 & 21 & $q$ & MO & 5 & 24 & 0 & 7 & 20.41 & 7 & 25.18 & 3 \\
\hline 11 & 38 & $q$ & MO & 2 & 30 & 0 & 7 & 22.34 & 5 & 31.81 & 24 \\
\hline 12 & 46 & $q$ & MO & 10 & 36 & 0 & 8 & 26.36 & 7 & 28.05 & 10 \\
\hline 13 & 17 & 8 & MO & 10 & 12 & 0 & 8 & 23.51 & 10 & 35.28 & 2 \\
\hline 14 & 30 & $q$ & MO & 10 & 12 & 1 & 5 & 26.43 & 7 & 23.30 & 24 \\
\hline 15 & 39 & 8 & MO & 10 & 66 & 0 & 8 & 27.15 & 1 & 35.28 & 2 \\
\hline 16 & 37 & 9 & MO & 9 & 30 & 0 & 8 & 25.23 & 7 & 33.70 & 48 \\
\hline 17 & 50 & $q$ & MO & 14 & 12 & 0 & 8 & 21.59 & 21 & 26.92 & 5 \\
\hline 18 & 52 & 9 & MO & 14 & 26 & 3 & 8 & 22.08 & 5 & 30.71 & 60 \\
\hline 19 & 35 & 9 & MO & 25 & 52 & 0 & 10 & 25.05 & 1 & 31.69 & 8 \\
\hline 20 & 58 & 9 & MO & 15 & 21 & 0 & 8 & 27.09 & 7 & 29.18 & 14 \\
\hline 21 & 35 & $q$ & MA & 6 & 20 & 2 & 10 & 29.33 & 20 & 29.67 & 20 \\
\hline Mean & 37.52 & & & 13.48 & 32.10 & & 8.14 & 23.74 & 7.62 & 28.04 & 18.43 \\
\hline SD & 10.34 & & & 8.61 & 23.23 & & 1.20 & 3.09 & 4.95 & 5.00 & 23.33 \\
\hline
\end{tabular}


Table 2: Demographic data on 21 migraineurs, whose samples from both the ictal and the interictal periods were analysed. The age, gender, type of migraine (with or without aura), disease duration (years), attack frequency, allodynia, VAS-score, PACAP-38-LI in plasma samples $(\mathrm{fmol} / \mathrm{ml})$ originating from interictal and ictal phases, the time of the previous attack before interictal blood sampling (days) and the duration of the present headache (hours) are shown for each patient. MA: migraine with aura; MO: migraine without aura. Allodynia: 0: absence of allodynia; 1: mild allodynia; 2 : moderate allodynia; 3: serious allodynia
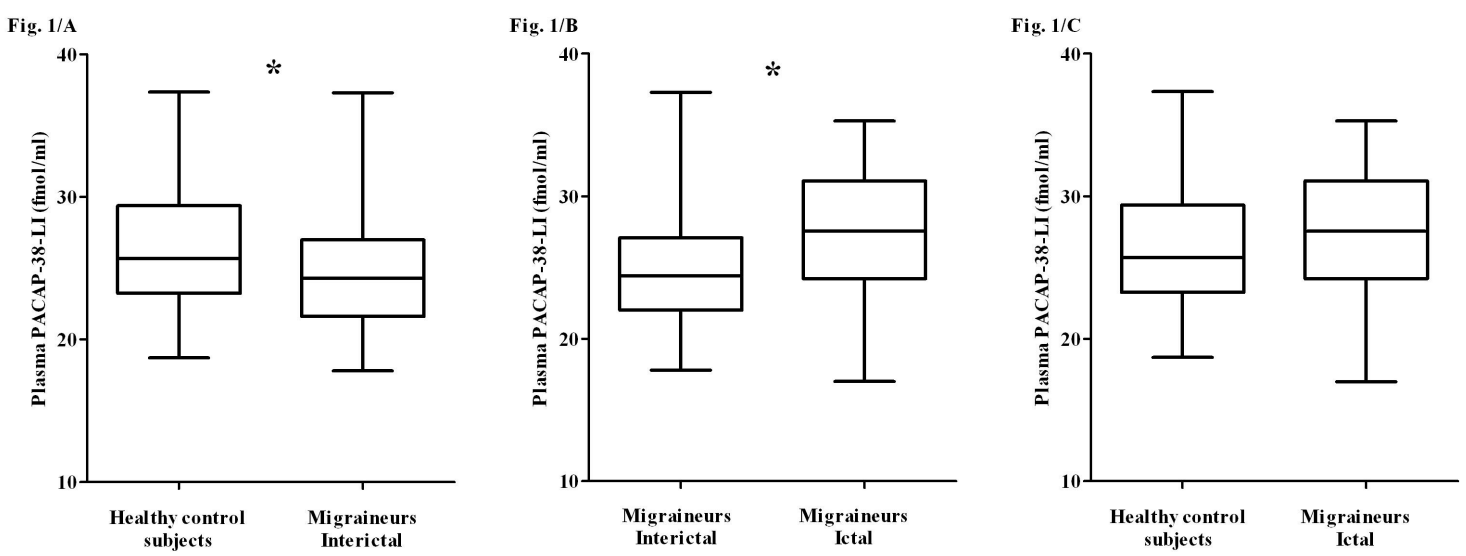

Fig. 1: PACAP-38-LI ( $\mathrm{fmol} / \mathrm{ml})$ was determined by RIA in the plasma of the migraineur groups in comparison with those of healthy volunteers. Boxes indicate PACAP-38-LI (median $\pm \mathrm{SD}$, minimum and maximum values) of healthy control subjects $(n=40)$, and of migraineurs $(n=87)$ during the interictal $(n=80)$ and ictal periods $(n=28)$. Significant PACAP38-LI decrease was observed between the control vs. the interictal group with Student's unpaired t-test, $\mathrm{p}<0.011$ (A). To except the interictal data of the paired samples, the interictal $(\mathrm{n}=59)$ vs. the ictal $(\mathrm{n}=28)$ group comparison showed significantly higher PACAP-38-LI during migraine attacks with Student's unpaired t-test, $p<0.009$ (B). There were no significant PACAP-38-LI differences between the control and the ictal group with Student's t-test for unpaired comparisons, $\mathrm{p}<0.447$ (C). 


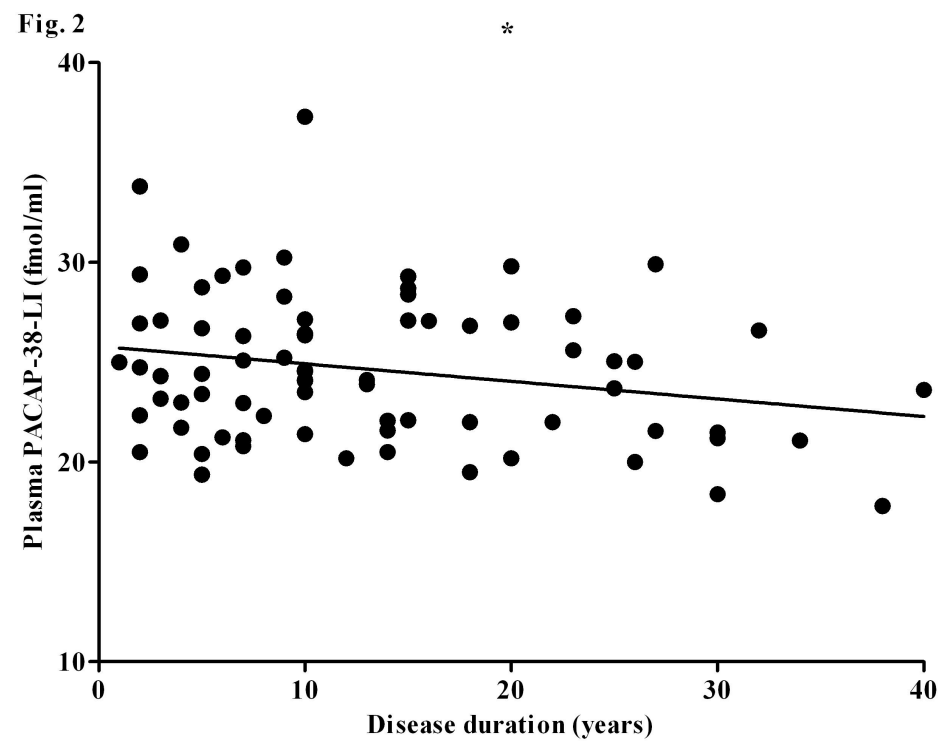

Fig. 2: Interictal plasma PACAP-38-LI ( $\mathrm{fmol} / \mathrm{ml}$ ) depending on the duration of the migraine disorder in the group of migraineurs $(n=87)$. A negative correlation was observed with linear regression on the graph, $\mathrm{p}<0.044$. 
Fig. 3/A.

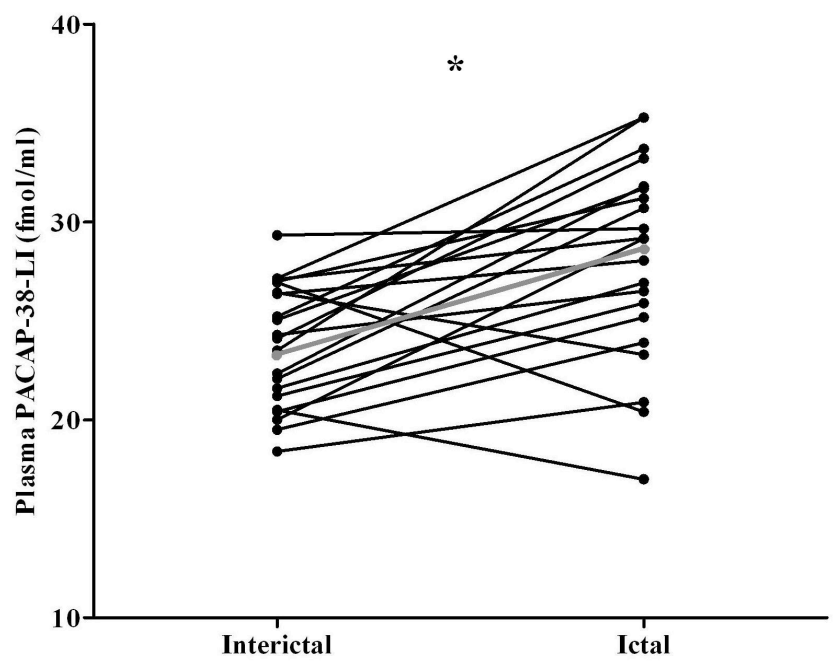

Fig. 3/B.

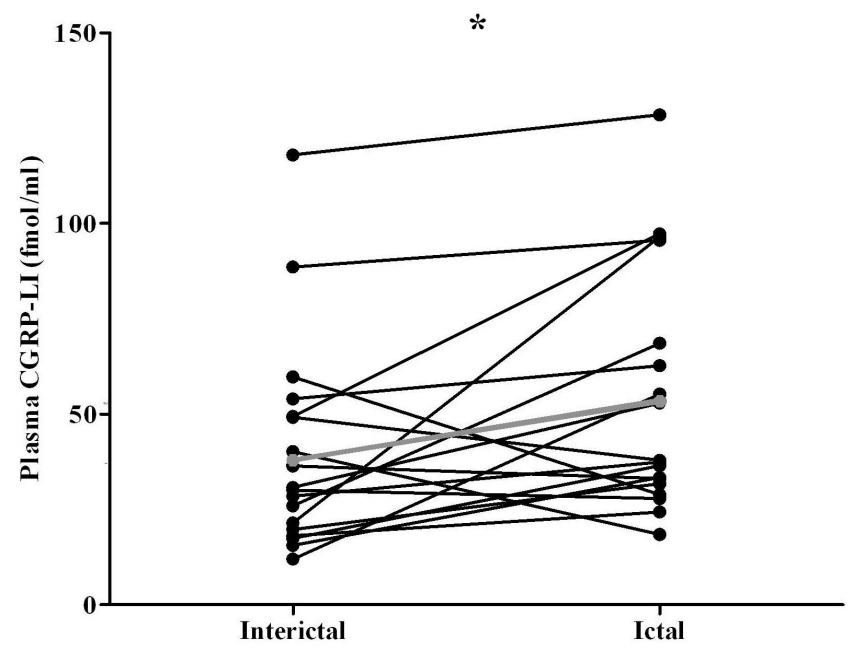

Fig. 3: PACAP-38-LI (fmol/ml) was determined by RIA on plasma samples from migraineurs in both interictal and ictal periods. A: Plots of individual data for each patient. A significant difference was observed between the levels in the two phases with Student's paired t-test, $\mathrm{p}<0.001$.

CGRP-LI ( $\mathrm{fmol} / \mathrm{ml}$ ) was determined by RIA on plasma samples from migraineurs in both interictal and ictal periods. B: Plots of individual data for each patient $(n=18)$. A significant difference was observed between the levels in the two phases with Wilcoxon-test, $\mathrm{p}<0.035$. The thick grey lines represent the mean values. 


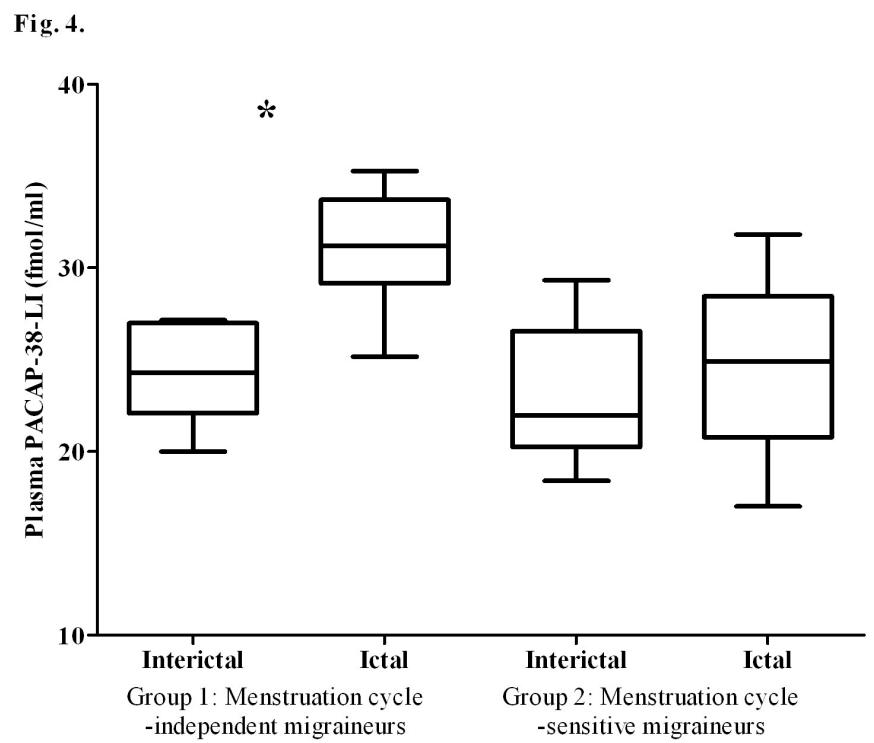

Fig. 5.

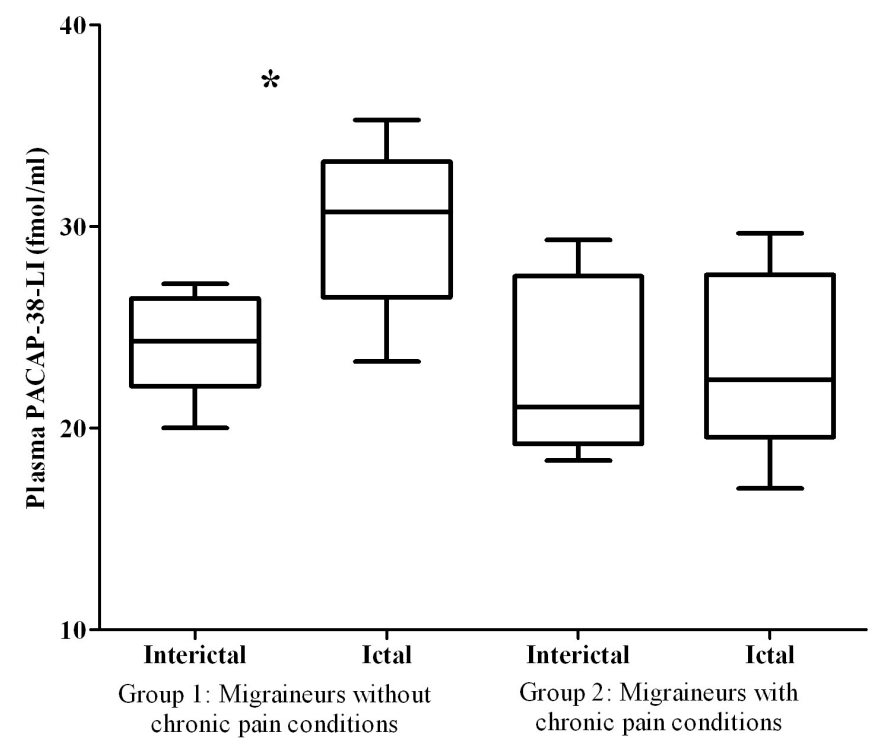

Fig. 4: Plasma PACAP-38-LI (fmol $/ \mathrm{ml})$ in the interictal and ictal periods of two subpopulations of 21 migraineurs, characterized on the basis of the menstruation cycle dependence. Group 1: menstruation cycle-independent migraineurs $(n=11)$; group 2: migraine patients, whose headache was sensitive to their menstruation $(n=10)$. Each box represents the median \pm SD, minimum and maximum values of the results. A significant difference in PACAP-38-LI was observed between the interictal and ictal phases in group 1 with Student's paired t-test, $\mathrm{p}<0.00002$.

Fig. 5: Plasma PACAP-38-LI (fmol $/ \mathrm{ml})$ in the interictal and ictal periods of two subpopulations of 21 migraineurs characterized on the basis of chronic pain conditions. Group 1: patients without chronic low back pain $(n=15)$; group 2: patients with simultaneous 
low back pain $(n=6)$. Each box represents the median $\pm S D$, minimum and maximum values of the results. A significant difference in PACAP-38-LI was observed between the interictal and ictal phases in group 1 with Student's paired t-test, $p<0.00005$.

\section{Article Highlights}

1. The PACAP-38 has an important role in the mechanisms of migraine attack.

2. A significantly lower PACAP-38 concentration in the interictal plasma of the migraineurs as compared with the healthy controls is associated with the duration of migraine disease.

3. The elevated plasma PACAP-38 level in the ictal phase relative to the attack-free period is attributable to the releasing peptide from the PACAP-containing neurons, which can contribute to the development and/or the aggravation of migraine attacks. 